\title{
PYLORIC STENOSIS
}

\section{BY}

\author{
J. A. BALINT, M.B., M.R.C.P.
}

Medical Registrar, Charing Cross Hospital

AND

M. P. SPENCE, M.B., M.R.C.P. Senior Medical Registrar, Middlesex Hospital

From the Gastro-enterological Unit, Ceniral Middlesex Hospital, London

Pyloric stenosis is a condition in which there is obstruction to the emptying of the stomach due to an organic lesion in the region of the pylorus. The clinical features of a consecutive series of cases in the adult have never been recorded. This lack of study of such an important condition may be due, in part, to the adequacy of standard descriptions based on clinical impression. Their inadequacy in one respect, the incidence of diarrhoea, prompted the present investigation.

\section{Methods}

Major and minor diagnostic criteria were formulated before the review was undertaken. Cases were not included in the series unless two major or one major and two minor criteria were satisfied. The major criteria were: (1) a classical history-that is, the persistent vomiting of large amounts at times when the stomach should be empty, or nearly so, usually containing recognizable residues of food eaten some hours previously or accompanied by offensive eructation; (2) the presence of visible gastric peristalsis; (3) the mean daily volume of the gastric residue* exceeding $1,000 \mathrm{ml}$. on the first or last three days on which aspiration was performed ; (4) the stomach emptying by less than one-third in two hours, less than a half in three hours, or less than two-thirds in four hours, as estimated by the radiologist who performed the bariummeal examination; and (5) the finding at operation or necropsy of considerable narrowing of the lumen in the region of the pylorus.

The minor criteria were: (1) a suggestive historythat is, persistent vomiting which almost satisfied the first major criterion; (2) the presence of a gastric succussion splash; (3) mean daily gastric residues exceeding $750 \mathrm{ml}$. on the first or last three days; and (4) the presence of alkalaemia as shown by a serum alkali reserve of more than $35 \mathrm{mEq} / \mathrm{l}$. or a serum chloride concentration of less than $85 \mathrm{mEq} / 1$.

In the years $1950-5$ inclusive 146 adult patients were discharged from the wards of the Central Middlesex Hospital with a diagnosis of pyloric stenosis. The records of these patients have been examined and 28 rejected because they failed to satisfy the necessary criteria. Data on the remaining 118 patients $(86$ men and 32 women) obtained from the hospital records have been analysed and form the basis of the present study. In no case was the site of the obstruction distal to the biliary ampulla or clearly proximal to the pylorus.

\footnotetext{
*At the Central Middlesex Hospital gastric aspiration was usually performed nightly some hours after the last meal, occasionally in the morning before breakfast, and rarely at other times to relieve distress. The volume of any vomitus has been added to that of the aspirate of the day. This is justified, as vomiting in hospital probably represented inadequate aspiration or was provoked by passage of the tube.
}

\section{Aetiology}

The cause of the pyloric stenosis was established by laparotomy in 115 patients, at necropsy in two, and by radiology alone in one. Benign prepyloric and pyloric ulcers were classified as duodenal because distinction was impossible, the opinions of surgeon, pathologist, and radiologist often being divided on the location of the pylorus. On this basis duodenal ulceration was the cause of stenosis in 95 instances. There were coincident gastric ulcers remote from the pylorus in only four. An actual ulcer crater was found in 83 and was described as large in 41 . In four further patients, although it was not discovered at the time of operation, a crater was probably present as there was a large inflammatory mass around the duodenum. In four others only scarring was noted at the pylorus, but as they were all treated by gastro-enterostomy the duodenum was not inspected from within. In two no comment on the activity of the ulcer was recorded. One was treated medically, while in the last patient a healed duodenal ulcer and an active gastric ulcer on the lesser curve were found at necropsy.

A gastric ulcer remote from the pylorus was the cause of obstruction in seven patients. In all of these laparotomy revealed a mass of fibrous tissue extending along the lesser curve and enveloping the pylorus.

In 13 cases pyloric obstruction was due to carcinoma of the pyloric antrum. In two it was due to kinking of the duodenum which had become adherent to a chronically inflamed gall-bladder. In the remaining patient it was due to a congenital diaphragmatic constriction at the pylorus.

\section{Symptomo}

The incidence of various symptoms is shown in Fig. 1. Vomiting attributable to pyloric stenosis occurred in all but three patients, being a presenting symptom in 105 and copious in at least 60 . The presence of recognizable residues of food eaten 12 or more hours previously was recorded in only 18 cases. It has been stated (Crohn, 1927 ; Hurst and Stewart,

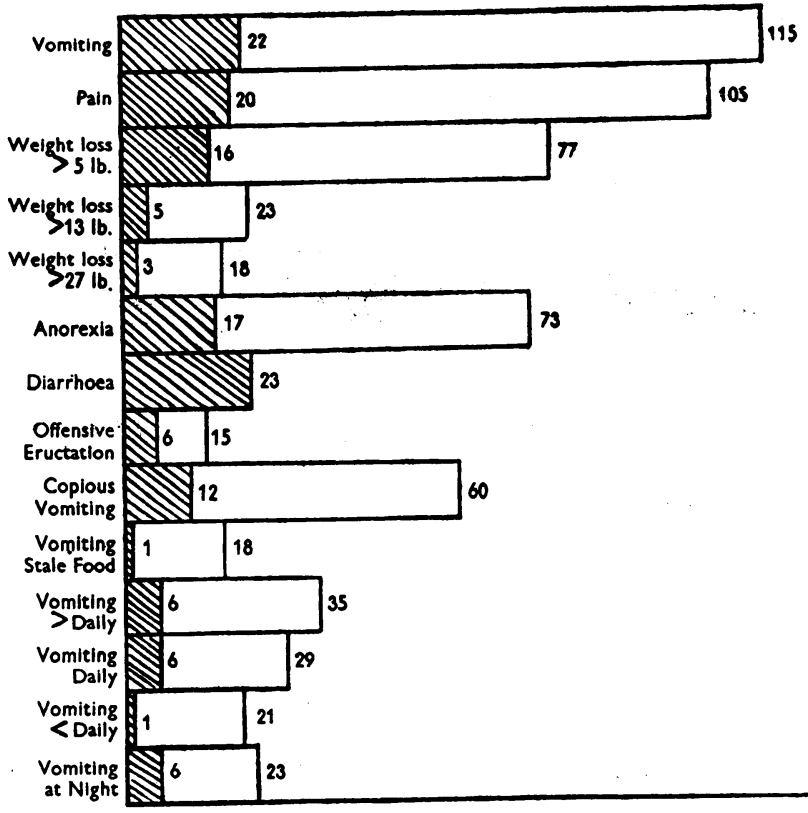

FiG. 1.-Incidence of various symptoms in pyloric stenosis due to all causes. Hatching= Cases with diarrhoea. 
1929) that with increasing gastric decompensation vomiting becomes less frequent but more copious. This was observed in a minority of the patients in the present series. In some cases vomiting occurred with the same frequency throughout the illness, in some it coincided with exacerbation of ulcer pain, and in some its frequency increased. A predominant pattern was discernible in 85 cases, with daily vomiting in 29 , more frequent than daily in 35, and occasional in 21 .

Pain of ulcer type had occurred in 105 patients, including 90 of the 95 with duodenal ulcers. Of the latter it was severe in 31 , moderate in 34 , and mild in 17 ; no assessment of severity could be made in eight. Among the seven gastric ulcer patients pain was severe in four and mild, moderate, or indefinite in one each. Of the 13 with carcinoma, seven did not complain of pain, in three it was mild, and in three it was moderate. Both the patients with pyloric stenosis due to gallbladder disease gave a history of ulcer-type pain.

The first symptoms (usually pain, sometimes perforation or haemorrhage) attributable to duodenal ulceration preceded admission for pyloric stenosis by 10 or more years in 53 cases and by less than five years in only 18.

Anorexia was present in 73 patients. 77 had lost $5 \mathrm{lb}$. $(2.3 \mathrm{~kg}$.) or more in weight. In 18 of these the loss exceeded $27 \mathrm{lb}$. (12.2 kg.) and in a further 23 it exceeded $13 \mathrm{lb}$. $(5.9 \mathrm{~kg}$.). Offensive eructation was noted in 15 .

Diarrhoea occurred in 23 patients, excluding those with an obvious cause such as idiopathic steatorrhoea or sensitivity to antacids. In six it was severe enough to be a presenting symptom-alone in two, with vomiting in three, and with heartburn in one. In two patients there was a long-standing history of diarrhoea, starting 4 and 15 years before vomiting and relieved by partial gastrectomy. More usually there had been loose stools for a few days, sometimes alternating with bouts of constipation. The frequency of other symptoms in the 23 patients with diarrhoea was similar in most respects to that in the series as a whole, as shown in Fig. 1.

The duration of obstructive symptoms before admission to hospital is shown in Table I. It was less than one month in 37 patients, one to three months in 35 , and longer than one year in only 14 . The relative

TABLE I.-Duration of Obstructive Symptoms Prior to Admission for Pyloric Stenosis

\begin{tabular}{|c|c|c|c|c|c|c|}
\hline Months: & 0 & $1-$ & $3-$ & $12+$ & Unknown & Total \\
\hline $\begin{array}{l}\text { Wholo series .. } \\
\text { Cases with diarrhoea }\end{array}$ & $\begin{array}{r}37 \\
5\end{array}$ & $\begin{array}{l}35 \\
12\end{array}$ & 27 & $\begin{array}{r}13 \\
1\end{array}$ & $\begin{array}{l}6 \\
1\end{array}$ & $\begin{array}{r}118 \\
23\end{array}$ \\
\hline
\end{tabular}

preponderance of cases with 1-3 months' history suggesting obstruction among patients with diarrhoea is statistically of borderline significance. There does not seem to be any clear-cut explanation for this finding, which is therefore probably fortuitous.

The annual incidence of episodes of perforation and of major haemorrhage (haematemesis, melaena, or both) in the 10 years before admission for pyloric stenosis is shown in Table II. The 14 perforations (all in duodenal ulcer cases) were distributed equally between the first and second halves of this period, so that there was no marked tendency for stenosis to follow shortly after perforation. In contrast, 39 of the
TABLB II.-Annual Incidence of Perforation and Haemorrhage in the Past Histories of All Patients in the Series, Before Admission for Pyloric Stenosis

\begin{tabular}{|c|c|c|c|c|c|c|c|}
\hline Year: & 1 & 2 & 3 & 4 & 5 & $6-10^{*}$ & Total \\
\hline $\begin{array}{c}\text { Cases of haemorrhage } \\
" \text { " perforation }\end{array}$ & $\begin{array}{r}22 \\
4\end{array}$ & $\begin{array}{l}5 \\
3\end{array}$ & 4 & 4 & 4 & $\begin{array}{l}1.4 \\
1.4\end{array}$ & $\begin{array}{l}46 \\
14\end{array}$ \\
\hline
\end{tabular}

46 instances of major haemorrhage occurred within five years of the date of entry into hospital, 22 of them within one year.

\section{Signs}

The incidence of the three signs mainly associated with pyloric stenosis is shown in Fig. 2. A gastric succussion splash was noted in 66 of the 118 patients and visible gastric peristalsis in 33 . Obvious dehydration was less c o m m o $\mathrm{n}$, being noted in only 29 . $T h$ e diagnosis of pyloric stenosis was often made in the absence of confirmatory physical signs.

\section{Radiology and} Blood Investigations

A barium - meal examination w a s performed in 93 of the 118 cases and showed evidence of delayed emptying in 79. Anaemia was com mon and a raised haemoglobin level rare (Fig. 2). In 45 of the 105 patients tested the

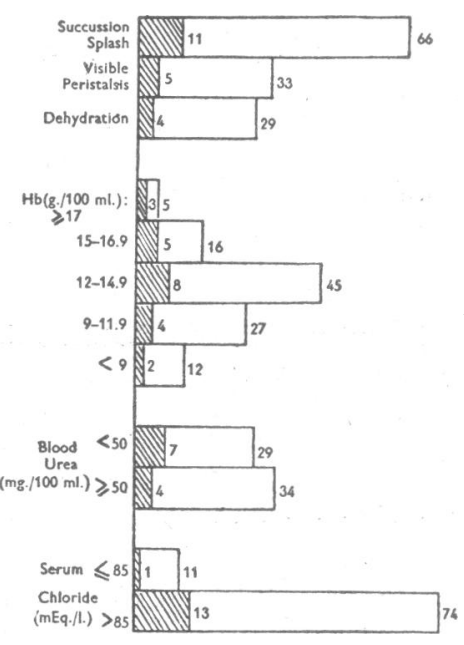

FIG. 2.-Incidence of abnormal physical signs and results of blood investigations in the whole series. investigations in the whole series. haemoglobin level was between 12 and 14.9 g. per $100 \mathrm{ml}$., in 27 between 9 and $11.9 \mathrm{~g}$. per $100 \mathrm{ml}$., and in 12 less than $9 \mathrm{~g}$. per $100 \mathrm{ml}$. Levels of 15 to 16.9 per $100 \mathrm{ml}$. occurred in 16 patients and higher levels in only five.

The blood urea was raised to $50 \mathrm{mg}$. per $100 \mathrm{ml}$. or more in about half the cases tested (34 of 63, Fig. 2). The serum bicarbonate level 、 $a$ s estimated in only 33 ; in 27 it was $30 \mathrm{mEq} / 1$. or higher. The serum chloride level was rarely depressed.

\section{Age and Sex Distribution}

The number of patients in different age and diagnostic groups is shown in Table III. Only 14 patients were under 40 , and 63 were between 40 and 59. This pattern reflects that of the duodenal ulcer cases because of their numerical preponderance, as does the sex distribution, approximately three males to one female (Table IV). The numbers in the other diagnostic groups are too small for separate analysis.

TABLE III.-Age Distribution in Diagnostic Groups

\begin{tabular}{|c|c|c|c|c|c|c|}
\hline Age (Years): & $0-39$ & $40-49$ & $50-59$ & $60-69$ & $70+$ & Total \\
\hline $\begin{array}{ll}\text { Duodenal ulcer } & . \\
\text { Gastric } & \quad \\
\text { Carcinoma" } & \because \\
\text { Other } & . .\end{array}$ & $\begin{array}{l}13 \\
1 \\
0 \\
0\end{array}$ & $\begin{array}{r}27 \\
0 \\
3 \\
1\end{array}$ & $\begin{array}{r}28 \\
2 \\
2 \\
0\end{array}$ & $\begin{array}{r}14 \\
3 \\
3 \\
0\end{array}$ & $\begin{array}{r}13 \\
1 \\
5 \\
2\end{array}$ & $\begin{array}{r}95 \\
\\
13 \\
3 \\
3\end{array}$ \\
\hline Total & 14 & 31 & 32 & 20 & 21 & 118 \\
\hline
\end{tabular}


Table IV.-Sex Distribution of Patients in the Different Aetiological Groups

\begin{tabular}{ll|r|r|c|c}
\hline & \multicolumn{2}{|c|}{ Whole Series } & \multicolumn{2}{c}{ Cases with Diarrhoea } \\
\cline { 3 - 5 } \cline { 5 - 6 } & Male & Female & Male & Female \\
\hline Duodenal ulcer & $\ldots$ & 72 & 23 & 17 & 5 \\
Gastric & $\ldots$ & 6 & 1 & & 1 \\
Carcinoma & $\ldots$ & 8 & 5 & & \\
Other .. &. & & 3 & & \\
\hline
\end{tabular}

\section{Diagnosis}

Exactly half the patients were first seen in the out-patient department, and the presence of pyloric stenosis was recognized before admission to hospital in most of these. In 11 of the other 59, admitted as emergencies, the provisional diagnosis referred only to the underlying lesion, no special significance being attached to the vomiting. In a further seven an initial diagnosis of major haematemesis was probably incorrect, because the haemoglobin level remained normal and there was no melaena. In three of these obstruction was not suspected, while in the other four both conditions were diagnosed. Pyloric stenosis was diagnosed on admission in the remaining 41 . In six of these the additional diagnosis of haematemesis was made and may have been correct.

In most respects, patients in different aetiological groups presented with similar symptoms, physical signs, and laboratory findings. The nature of the underlying lesion, when not already known, was established by radiology or laparotomy. One of the few features of value in the clinical diagnosis of malignancy was the length of time from the first symptom suggestive of peptic ulceration. Of the 14 patients in whom this did not exceed one year, nine had carcinoma. The other four with carcinoma gave histories of dyspepsia of up to 12 years' duration. In none of these had obstructive symptoms been present for more than a year. In one patient the presence of a palpable mass in the epigastrium established the diagnosis of carcinoma.

It was anticipated that the volume of the gastric residue would tend to decrease from day to day on in-patient medical treatment, including gastric aspiration or lavage, and that exceptions would indicate malignancy. This was not borne out by our findings. The volume of the aspirate on the first three days after admission and the last three before operation could be compared in 67 patients. In 22 there was an increase of between 250 and $1,000 \mathrm{ml}$. a day ; the underlying lesion was cancerous in only four of these. An increase of more than $1,000 \mathrm{ml}$. a day was found in six, of whom only one had a carcinoma.

\section{Treatment}

Duodenal Ulcer Patients. - Of the 95 patients with pyloric stenosis due to duodenal ulcer, $88^{*}$ were treated by surgery during their first admission for obstruction. Partial gastrectomy was performed in 68 with only one post-operative death. Twenty, mostly elderly or very ill, were treated by gastro-enterostomy, again with one death. Four were treated medically-that is, bed rest, nightly gastric aspiration, and milk feeds. Three of these-required operative relief of their obstruction within nine months. The remaining three died before surgical relief was possible.

\footnotetext{
*Three had been treated medically in the Central Middlesex Hospital before 1950 .
}

Gastric Ulcer Patients. - Of the seven patients in this group, four were treated by partial gastrectomy. One died before operation was possible. Two were treated medically; one required partial gastrectomy after three years and the other was moribund from emphysema two years later.

Carcinoma Patients.-At the first admission for pyloric stenosis due to carcinoma, total gastrectomy was performed in two patients, and partial gastrectomy in three. Gastro-enterostomy was the only operation possible in six. There was one post-operative death in each group. One patient, thought to have a duodenal ulcer, was treated medically at the first admission. Carcinoma was an unexpected finding at partial gastrectomy eight months later. The remaining patient was never fit for surgery.

Other Conditions.--In both the patients in whom adhesion to a chronically inflamed gall-bladder had caused pyloric stenosis it was possible to free the duodenum surgically: one made an excellent recovery, one died from cerebral thrombosis after operation. The congenital diaphragmatic constriction was not detected at laparotomy and was diagnosed at necropsy following fatal pulmonary embolism.

\section{Discussion}

Obstruction to gastric emptying near but not necessarily at the pylorus was the common feature of the patients in this series. By definition all had pyloric stenosis. This use of the term, although anatomically inexact, is both customary and logical, for the precise position of the stenosis does not affect the clinical management of the case, nor can it always be determined. Narrowing in this region is of importance only if it impairs gastric emptying, and the criteria of stenosis used in the present study were not satisfied unless this disturbance of function was present. The criteria being stringent, the diagnosis was reasonably certain when these were satisfied. This implies the exclusion of patients with pyloric stenosis of slight degree to whom our conclusions may not apply. Probably some others were excluded because the available data were incomplete. All those accepted had an organic lesion in the vicinity of the pylorus.

During the period covered by the present series an average of 17 patients with pyloric stenosis due to benign ulceration were seen each year at the Central Middlesex Hospital. Avery Jones and Pollak (1945) have calculated from the hospital statistics for 1943-4 that at least 500 cases of peptic ulceration per annum occur in the population served by that hospital. This figure is almost certainly too low for the period covered by the present series. It follows that less than $3.4 \%$ of peptic ulcer subjects ultimately develop pyloric stenosis of a severity sufficient to satisfy our criteria. The true rate may be in the region of $2 \%$. Similar calculations for duodenal and gastric ulcers separately give a maximal possible incidence of $4.5 \%$ and $0.7 \%$ respectively. These rates are lower than would be found if the disease were allowed to run its natural course. Early elective surgery has removed some potential cases of obstruction from the population at risk.

In 5,000 consecutive necropsies at Leeds, Hurst and Stewart (1929) found peptic ulceration in 403, of which $63(15.6 \%)$ had pyloric stenosis. The discrepancy between this incidence and that calculated on the basis of the present series can hardly be explained by a higher 
rate of elective surgery. Furthermore, the Leeds figures refer to the time when the mortality from pyloric stenosis was falling owing to improvements in surgical technique. Under these circumstances necropsy material would underestimate the true incidence. It is therefore probable that many of the Leeds cases did not have gastric retention of a degree that would have permitted inclusion in the present series. Hurst and Stewart stated, and we confirm, that clinical cases of pyloric stenosis usually have active ulcers. That the lesions had healed in half their necropsy cases confirms that these included many examples of narrowing without obstruction.

In accordance with modern practice (Illingworth et al., 1944) all ulcers have been classified as duodenal except those clearly in the stomach and separate from the pylorus. In the seven instances of stenosis due to gastric ulcer the obstruction was at the pylorus and therefore remote from the causative lesion. Considerable shortening of the lesser curve was invariably present. On the radiograph it appeared as though obstruction had been caused by kinking of the pylorus, but at operation this was always seen to be involved in extensive inflammatory fibrosis. Six of the seven patients were men. Hinds and Kemp Harper (1952) reported 10 similar cases, all in men, and attributed vomiting, which occurred in nine, to stagnation in the pouch formed by the inferior portion of the stomach. The contrast in behaviour of gastric ulcer in the two sexes is striking. Pyloric stenosis from this cause occurs predominantly in men and hour-glass constriction in women.

Coincident gastric ulcers occurred in four $(4.2 \%)$ of the duodenal ulcer cases. They were found in 16 $(6.7 \%)$ of a comparable series of 240 consecutive patients on whom operations for duodenal ulcer without stenosis were performed at the Central Middlesex Hospital in the years 1955-6. These figures do not support the contention of Daintree Johnson (1955) and of Dragstedt $(1956,1958)$ that gastric retention favours the development of gastric ulceration.

The relative importance of cicatricial narrowing, infiammatory swelling around an active ulcer, spasm, and impaired motility in the production of pyloric obstruction associated with peptic ulceration has been the subject of much speculation. Hurst and Stewart's (1929) statement that active ulceration is almost always present in clinical pyloric stenosis is confirmed by our observations. Therefore cicatricial narrowing is not a sufficient cause of gastric retention and some additional factor associated with active ulceration is necessary. Berkman (1923) reported that no obstruction was found at operation in $58.3 \%$ of patients with pyloric stenosis caused by peptic ulceration. By contrast, $12.5 \%$ of 564 ulcer cases without gastric retention had a narrowed pylorus at operation. He concluded that constriction is of no importance so long as the motor function of the stomach remains adequate. Illingworth (1953) also considered that stenosis due to scarring alone was uncommon and that spasm usually played a part, especially in cases with gastric ulcer. The high incidence of very large ulcers found in the Central Middlesex Hospital series suggests that inflammatory swelling is of importance in the production of pyloric stenosis.

The frequency of chronic perforation of duodenal ulcers in cases with pyloric stenosis has been stressed by Berkman (1921, 1923). This point was not investigated in the present series. Contrary to Crohn's (1927) view, our evidence does not suggest that acute perforation is an important factor, for its incidence was no higher in the years just before admission to hospital for pyloric stenosis than it had been some years previously (Table II).

Vomiting was the commonest symptom, and usually was copious. There was rarely a definite history of the vomitus having contained residue of food eaten 12 or more hours previously. Pain of ulcer type was a complaint in all but 5 of the 102 patients with benign peptic ulcer, and often was severe. We have not confirmed the opinion sometimes expressed (Berkman, 1923 ; Hurst and Stewart, 1929; Bockus, 1943; Illingworth, 1953) that the onset of pyloric stenosis is usually marked by loss of the normal periodicity of symptoms. Our evidence on this point, however, is not entirely satisfactory.

Bockus (1943), Hurst (1946), and others have stated that constipation, often severe, is invariable in pyloric stenosis. Crohn (1927) described the occasional occurrence of diarrhoea. In the present series there were 23 patients in whom diarrhoea was attributable to pyloric stenosis. It was usually slight, but in six it was severe enough to be a presenting symptom. The high incidence of offensive eructation in the diarrhoea cases, although statistically of only borderline significance, suggests that stale food in the stomach leads to the production of some substance irritant to the intestine. In other respects the findings in the diarrhoea cases do not differ substantially from those in the series as a whole. In particular the similarity of the haemoglobin, blood urea, and chloride levels (Fig. 2) suggests that neither haemorrhage nor electrolyte imbalance plays a part in producing the bowel disturbance.

Our findings on the frequency of specific physical signs agree with the views of Parsons and Watkinson (1954). A gastric succussion splash was found in about half the patients, while visible gastric peristalsis and obvious dehydration were each reported in about a quarter.

The relationship between radiological and other evidence of delayed gastric emptying has been studied by Bockus (1943) and Illingworth (1953). In general the correlation is good, but there are discrepancies in mild cases. In the present series barium-meal examination after the onset of symptoms of pyloric stenosis failed to show evidence of delayed gastric emptying in one-seventh of the cases.

Bockus (1943) comments on the frequency of anaemia in pyloric stenosis, and our findings confirm this. The blood-urea level was raised in over half the patients in whom it was estimated. This suggests that metabolic disturbance due to water and electrolyte deficiency was common.

Difficulties in diagnosis were encountered in one-third of the emergency admission cases. In particular a mistaken diagnosis of major haematemesis was made on seven occasions when the vomiting of brown fluid, subsequently shown to be due to pyloric stenosis, was described in the account of the events leading to admission. Similar errors could explain the sharp rise in the apparent incidence of haematemesis in the years immediately before the diagnosis of gastric retention (Table II).

One clinical factor analysed in this series was found to be of some value in detecting underlying cancer. If 
the first symptom of gastro-duodenal disease occurred less than a year before admission for pyloric stenosis there was an almost even chance of malignancy. Bockus (1943) records similar findings. Neither the length of obstructive history nor the failure of regular aspiration to reduce the volume of the gastric residue was of value. A history of previous ulcer dyspepsia of some years' standing did not preclude carcinoma. As surgery is the only certain remedy for pyloric stenosis, whatever the cause, this clinical differentiation is not of great importance.

In the present series medical treatment, with repeated gastric aspiration or lavage, replacement of fluid and electrolyte loss, bed rest and frequent milk feeds, although an essential preliminary to surgery, was rarely tried as definitive therapy and never proved of lasting value. Emery and Monroe (1935) found benefit from such measures in $38.6 \%$ of their cases but gave no precise definition or data on length of observation after treatment. Bockus (1943) stated that $50 \%$ of patients improved by medical measures would relapse and need operative relief of their obstruction. In view of the low mortality associated with modern surgery, other definitive measures have been largely superseded. There were only two deaths in the present series among 92 patients treated surgically for pyloric stenosis due to benign ulceration. By contrast, only 4 of the 13 with carcinoma left hospital after a potentially curative operation.

\section{Summary}

A precise definition of pyloric stenosis, and the diagnostic criteria, are given. The clinical, radiological, laboratory, and morbid anatomical findings in 118 consecutive cases of pyloric stenosis are reviewed. Active duodenal ulceration was the commonest cause.

Diarrhoea attributable to pyloric stenosis was found in $20 \%$ of the patients in the series. Its causation is discussed. In other respects previous descriptions of pyloric stenosis have, in general, been confirmed.

The definitive treatment was surgical in nearly all cases.

We thank Drs. F. Avery Jones and W. R. S. Doll for encouragement, helpful criticism, and advice in the preparation of this report. We are grateful to the other members of the staff of the Central Middlesex Hospital for permission to study the cases admitted under their care. We are indebted to Miss Barbara White, who performed the statistical analyses.

\section{REFERENCES}

Berkman, D. M. (1921). Med. Clin. N. Amer., 5, 411.

(1923). Coll. Pap. Mayo Clin., 15, 92.

Bockus, H. L. (1943) Gastro-enterology, vol. 1. Saunders, London.

Crohn, B. B. (1927). Affections of the Stomach. Saunders, Philadelphia.

Dragstedt, L. R. (1956). Amer. J. Roentgenol., 75, 219.

(1958). Brit: med. J., 1, 1234

Emery, E. S., jun., and Monroe, R. T. (1935). Arch. intern. Med. $55,271$.

Hinds, S. J., and Harper R. A. K. (1952). Brit. J. Radiol., 25,

451. .
Hurst, A. F. (1946). In F. W. Price's A Textbook of the Practice of Medicine, 7th ed. Oxford Univ. Press, London.

and Stewart, M. J. (1929). Gastric and Duodenal Ulcer. Oxford Univ. Press, London

Illingworth, C. F. W. (1953). Peptic Ulcer. E. and S. Livingstone Ltd., Edinburgh and London.

Scott, L. D. W., and Jamieson, R. A. (1944). Brit. med. J., 2, 655 .

Johnson, H. D. (1955). Lancet, 1, 266.

Jones, F. A., and Pollak, H. (1945). Brit. med. J., 1, 797.

Parsons, F. M., and Watkinson, G. (1954). Postgrad. med. J., 30, 145 .

\section{CHLOROQUINE PER RECTUM FOR MALARIA IN CHIILDREN \\ BY}

\section{J. BRUCE-CHWATT, O.B.E., M.D., M.P.H. D.T.M.\&H.* \\ AND}

\section{F. D. GIBSON, A.I.M.L.T.}

From the Federal Malaria Service, Lagos, Nigeria

The use of chloroquine in suppositories for the treatment of malaria in children was introduced seven years ago in to-day's Vietnam by Canet (1951). This method, advocated by Lavier and Schneider (1951), has subsequently been quite widely adopted in paediatric practice in French overseas territories. Nevertheless it is little known or used in other countries, and was not mentioned in the comprehensive monograph on chemotherapy of malaria by Covell, Coatney, Field, and Singh (1953).

As problems connected with treatment of malaria in children were recently reviewed by one of us in preparing a chapter on malaria for Trowell and Jelliffe's (1958) book on tropical paediatrics, it was proposed to assess the value of rectal administration of chloroquine on a selected group of hospitalized African children. We thought it would be of interest to evaluate not only the comparative parasiticidal action of the drug given per rectum or by mouth, but also to determine the respective rates of urinary excretion of the chloroquine base.

\section{Material and Technique}

The trial was carried out in the children's ward of the Royal Orthopaedic Hospital at Igbobi, near Lagos. Twenty-eight children who were admitted for various bone and joint diseases but who, on admission, were found to be also infected with malaria were selected for the trial. After a preliminary screening, the children, whose mean age was 6.8 years, were divided into two groups. One group of 10 received chloroquine sulphate by mouth in one single dose containing $300 \mathrm{mg}$. of chloroquine base. The other group, composed of 18 children, was subdivided, so that one subgroup comprising 12 children was given a single chloroquine sulphate suppository containing $300 \mathrm{mg}$. of base, while the other subgroup, consisting of six children, had one such suppository every day for five days, thus receiving a total dose of $1,500 \mathrm{mg}$. of chloroquine base.

All the children were on the same hospital diet, but the fluid intake was not controlled. The drugs were given personally by one of us, and thick blood films were taken daily for one week after the administration of chloroquine. The slides, stained with Giemsa, were examined for the presence of malaria parasites, their species, and the parasite density. The percentage of daily slides cleared of malaria parasites and the "clearance time" were used as an indication of the activity of the drug administered to each group. This method has been used for several similar investigations (Bruce-Chwatt, 1951 ; Bruce-Chwatt and Archibald, 1953 ; Bruce-Chwatt and Charles, 1957), and need not be described in detail.

The rate of absorption and excretion of the antimalarial was estimated from the amount of chloroquine base eliminated in daily samples of 24-hour urine during

*Now at the Division of Malaria Eradication, W.H.O., Geneva. 